\title{
HUBUNGAN PENGETAHUAN TENTANG ANTISIPASI CEDERA DENGAN PRAKTIK PENCEGAHAN CEDERA PADA ANAK USIA TODDLER DI RW 01 KELURAHAN MANGGAHANG WILAYAH PUSKESMAS JELEKONG KABUPATEN BANDUNG
}

\author{
*Dwi Hastuti \\ *Stikes Jenderal Achmad Yani Cimahi \\ J1. Terusan Jenderal Sudirman-Cimahi 40533 \\ Telp. 022-6631622, Fax. 022-6631624 \\ Email:dwi.hastuti@gmail.com
}

\begin{abstract}
Abstrak
Cedera adalah dampak dari agen eksternal yang menimbulkan kerusakan fisik maupun mental. Cedera termasuk salah satu dari beberapa penyebab utama morbiditas dan mortalitas pada anak di dunia. Prevalensi cedera pada tahun 2007 mencapai 7,5\% dan mengalami peningkatan tahun 2013 yaitu 8,5\%. Melihat karakteristik perkembangannya toddler lebih beresiko mengalami cedera. Hal ini dapat berdampak pada psikologis, terganggunya proses pertumbuhan dan perkembangannya dikemudian hari, menimbulkan kecacatan bahkan lebih fatal bisa menyebabkan kematian. Ibu yang memiliki pengetahuan tentang antisipasi cedera akan menentukan tindakan pencegahan cedera. Penelitian ini bertujuan untuk mengetahui hubungan pengetahuan ibu tentang antisipasi cedera dengan praktik pencegahan cedera pada anak usia toddler di RW 01 Kelurahan Manggahang Wilayah Puskesmas Jelekong Kabupaten Bandung. Metode penelitian yang digunakan adalah deskriptif korelatif dengan desain crosssectional, sampel dalam penelitian ini sebanyak 79 ibu. Data diperoleh secara langsung selanjutnya diolah dengan analisis bivariate yaitu Chi-Square. Hasil penelitian menunjukkan sebagian ibu berpengetahuan cukup tentang antisipasi cedera (44,3\%). Hasil uji Chi-Square diperoleh adanya hubungan antara pengetahuan ibu tentang antisipasi cedera dengan praktik pencegahan cedera pada anak usia toddler di RW 01 (P value $=0,000$ ). Disarankan para ibu untuk meningkatkan pengetahuan tentang antisipasi cidera sehingga ibu dapat melakukan tindakan dalam menjamin kesehatan, keamanan, dan keselamatan anak dalam beraktifitas sehingga anak terhindar dari bahaya cedera.
\end{abstract}

Kata kunci: Pengetahuan, Antisipasi Cedera, Praktik Pencegahan Cedera, Toddler Kepustakaan : 38 (2005-2016)

\begin{abstract}
Injury is the impact of external agents that cause physical or mental damage. Injury is one of the main causes of childhood morbidity and mortality in the world. The prevalence of injury in 2007 reached $7.5 \%$ and increased in 2013 by $8.5 \%$. Looking at the characteristics of development toddler more at risk of injury. This can have psychological effects, disruption of the growth process and its development in the future, causing even more fatal disability can cause death. Mothers who are knowledgeable about the anticipation of injury will determine the precautions of injury. This study aims to determine the relationship of mother knowledge about anticipation of injury with injury prevention practices in children aged toddler in RW 01 Kelurahan Manggahang Area Puskesmas Jelekong Bandung. The research method used descriptive correlative with crosssectional design, the sample in this study as 79 mothers. Data obtained directly then processed by bivariate analysis that is Chi-Square. The results showed that some mothers were knowledgeable about injury anticipation (44.3\%). Chi-Square test results obtained a relationship between mother's knowledge about anticipation of injury with injury prevention practices in children aged toddler in $R W 01(P$ value $=$ 0,000). Mothers suggest to increase knowledge about the anticipation of injuries so that mothers can take action in ensuring the health, safety, and safety of children in the activity so that children avoid the danger of injury.
\end{abstract}

Keywords: Knowledge, Injury Anticipation, Injury Prevention Practice, Toddler 


\section{PENDAHULUAN}

Indonesia merupakan salah satu negara berkembang yang memiliki prevalensi cedera cukup tinggi. Hasil Riset Kesehatan Dasar tahun 2007 melaporkan bahwa prevalensi nasional cedera mencapai $7,5 \%$. Persentase nasional tiga penyebab cedera terbanyak adalah jatuh $(58,0 \%)$, kecelakaan $(25,9 \%)$, dan terluka benda tajam $(20,6 \%)$ (Badan Litbang Depkes, 2008). Berdasarkan data Survei Kesehatan Nasional di Indonesia (2010) cedera menempati urutan ke 3 dari 10 penyakit penyebab kematian dan paling banyak dialami oleh anak usia toddler.

Cedera sering terjadi pada anak-anak, biasanya berawal dari rasa keingintahuan anak untuk menelusuri sesuatu dan bereksperimen yang tidak seimbang dengan kemampuan dalam memahami sesuatu atau bereaksi terhadap bahaya. Melihat karakteristik perkembangannya, anak usia toddler lebih beresiko mengalami cedera. Cedera pada anak usia toddler dapat mengakibatkan beberapa kondisi yaitu, dampak psikologis atau trauma pada anak, anak akan berhenti melakukan hal yang dapat membuatnya trauma dan takut sehingga dapat mengakibatkan terganggunya proses pertumbuhan dan mengalami keterlambatan dalam perkembangannya dikemudian hari, banyak anak yang mengalami cacat akibat cedera, cacat ini memiliki dampak buruk yang luar biasa pada perkembangan anak serta produktivitasnya di masa depannya, juga pada keuangan, dan emosi keluarga. Bahkan yang lebih fatal cedera bisa menyebabkan kematian.

Anak usia toddler sedang mengembangkan keterampilan motorik kasarnya yang membuat mereka bergerak terus, berlari, berjinjit, naik-turun tangga, memanjat, melompat, atau main dengan sepedanya.
Anak usia toddler juga mengalami peningkatan kemampuan motorik halus ketika mereka semakin terampil menggenggam, membuka atau menutup, atau melempar benda-benda yang ada disekelilingnya. Anak usia toddlermempunyai rasa ingin tahu yang besar dibanding dengan anak usia lainnya, padahal dia belum tahu dan belum berpengalaman dalam upaya melindungi diri dari bahaya kecelakaan (Supartini, 2004).

Menurut Riskesdas Kabupaten Bandung pada tahun 2013 prevalensi cedera menempati angka 12,9\% sedangkan di tahun 2007 Kabupaten Bandung menempati urutan ke 8 dari 14 Kabupaten di Provinsi Jawa Barat dengan prevalensi cedera yaitu sebanyak $8 \%$, persentasi menurut jenis cedera pada anak usia 1-4 tahun di Kabupaten Bandung adalah luka lecet $55,7 \%$, benturan $43,6 \%$, luka terbuka $14,7 \%$, terkilir $8,6 \%$, luka bakar $2,4 \%$, patah tulang $1,0 \%$, keracunan $0,5 \%$, dan anak usia toddler termasuk kedalam kategori usia tersebut.

Cedera toddler dapat dicegah salah satunya yaitu dengan pengawasan yang baik dari para orang tua (Arvin, 2000). Orangtua perlu mendapatkan bimbingan antisipasi terhadap kemungkinan terjadinya bahaya atau ancaman kecelakaan tersebut, menurut Supatini (2004) cedera pada anak usia toddler tidak terjadi apabila orang tua memiliki pengetahuan tentang tingkat tumbuh-kembang anak usia toddler.

Ibu yang memiliki pengetahuan akan menilai atau bersikap terhadap pengetahuan tersebut (Notoatmodjo, 2007). Berdasarkan hasil penelitian yang dilakukan oleh Atak, et.al (2010) yang menyatakan bahwa kejadian cedera anak terbanyak dialami oleh ibu dengan tingkat pengetahuan rendah. Semakin meningkatnya pengetahuan ibu, maka ibu akan makin dapat mengidentifikasi cedera 
pada anak. Dadang (2014) di Kabupaten Lamongan dalam penelitiannya tentang praktik pencegahan cedera pada anak usia toddler ditinjau dari pengetahuan orang tua didapatkan responden yang berpengetahuan rendah yaitu $15,91 \%$.

Notoatmodjo (2007) menjelaskan bahwa pengetahuan berperan dalam pembentukan sikap seseorang, pengetahuan membuat seseorang berpikir akan suatu objek atau stimulus. Adapun hasil penelitian yang dilakukan Aken et.al (2007) menjelaskan bahwa karakteristik ibu yaitu termasuk didalamnya sikap ibu, berpengaruh terhadap resiko cedera pada anak. Dimana sikap akan menentukan bagaimana ibu bertindak untuk melindungi anaknya dari cedera dengan melakukan tindakan berupa pengawasan yang berpengaruh terhadap kejadian cedera pada anak. Berdasarkan hasil penelitian yang dilakukan oleh Indarwati (2011) tentang karakteristik sikap responden terhadap pencegahan cedera pada anak usia toddler di Kabupaten Karanganyar didapatkan data 39,7 $\%$ orang tua bersikap negatif terhadap bahaya cedera anak usia toddler.

Puskesmas Jelekong adalah puskesmas non rawat inap di bawah naungan Dinas Kesehatan Kabupaten Bandung yang melakukan pelayanan kuratif dan rehabilitatif terpadu dengan pelaksanaan kegiatan promotif dan preventif (pencegahan). Berdasarkan studi pendahuluan yang dilakukan pada tanggal 29 Februari 2015 didapatkan data 6 bulan terakhir (September 2015-Februari 2016) didapatkan data jumlah anak usia toddleryang berobat yaitu sebanyak 473 anak, ternyata 48 anak datang dengan kasus cedera. Cedera ini berada pada urutan 9 dari 10 besar penyakit yang mana dapat diurutkan sebagai berikut ISPA $(34,77 \%)$, Diare $(13,15 \%)$, Febris $(8,02 \%)$, Faringitis
(7,93\%), Pneumonia (7,13\%), Dyspepsia $(6,57 \%)$, Gangguan Gigi (5,86\%), Dermatitis $(5,69 \%)$, Kasus Cedera (5,52\%), Gangguan lain pada kulit dan jaringan $(5,36 \%)$.

Perawat mempunyai peran penting dalam upaya penurunan angka kejadian cedera pada anak. Upaya yang dapat dilakukan petugas kesehatan untuk mengurangi cedera pada anak usia toddler menurut Supartini (2004) yaitu dengan memberikan bimbingan antisipasi cedera yang tepat, memberikan informasi dan pengetahuan pada ibu agar selalu waspada terhadap setiap gerak yang dilakukan oleh anak, memberikan alat bermain yang sesuai dan tidak membahayakan, serta melakukan pengawasan dengan memberi perhatian pada anak. Puskesmas Jelekong melakukan pengawasan dan pembinaan di posyandu-posyandu yang berada di Kelurahan Manggahang salah satunya di RW 01, dan belum ada program khusus mengenai pencegahan cedera. Menurut data tercatat kejadian cedera pada anak terbanyak didapatkan di RW 01 dibandingkan 5 RW lainnya yaitu sebanyak 27 kasus. Berdasarkan data tersebut peneliti ingin mengetahui hubunganpengetahuan dan sikap ibu tentang antisipasi cedera dengan praktik pencegahan cedera pada anak usia toddler.

\section{TINJAUAN PUSTAKA}

Pengetahuan adalah hasil mengingat suatu hal, termasuk mengingat kembali kejadian yang pernah dialami baik secara sengaja maupun tidak sengaja dan ini terjadi setelah orang melakukan pengamatan terhadap suatu objek tertentu (Mubarak, 2007). Pengetahuan mempengaruhi seseorang dalam melakukan tindakan. Apabila perilaku didasari oleh pengetahuan, kesadaran, dan sikap positif, maka perilaku tersebut akan bersikap 
langgeng (long lasting). Newcomb dalam Notoatmodjo (2003) menyatakan bahwa sikap merupakan kesiapan atau kesediaan untuk bertindak, dan bukan merupakan pelaksanaan motif tertentu. Orang tua dalam melakukan pengasuhan anak untuk menghindari cidera perlu dikaji dalam hal pengetahuannya tentang antisipasi cidera.

Antisipasi cedera adalah suatu ramalan mengenai suatu kondisi individu yang berisiko untuk mengalami cedera sebagai akibat dari kondisi lingkungan yang berhubungan dengan sumber-sumber adaptif dan pertahanan. Antisipasi cedera dapat dilakukan dengan menggambarkan apa saja hal-hal yang dapat menyebabkan cedera, apa saja jenis cedera yang dapat terjadi, apa bahayanya, serta apa yang akan dilakukan bila cedera itu terjadi. Adapun jenis cedera yang sering dialami pada anak usia toddler dan pertolongan pertamanya adalah jatuh, perdarahan, cedera pada leher dan tenggorok, cedera kepala, demam, keseleo, patah tulang, sendi bergeser (dislokasi), tersayat (teriris).

Luka yang terjadi pada anak biasanya disebabkan anak terjatuh atau tergelincir ketika bermain. Lantai rumah yang licin atau basah karena air atau minyak juga dapat menyebabkan anak jatuh. Selain itu, kegemaran anak bermain dengan benda-benda tajam, seperti garpu, gunting, jarum atau tusuk gigi juga juga dapat menyebabkan cedera (Ibrahim, Daud, Sulistijani, 1999). Menurut Kyle, Terri, Susan Carman, (2014); Widjaja (2002) dan Supartini, (2004) pencegahan cedera pada anak usia toddler dapat dilakukan dengan meningkatkan keamanan dan mencegah cedera. Cedera dapat dicegah jika orangtua mengerti hal-hal yang harus dilakukan untuk menghindari anak dari kecelakaan. Menurut Widjaja (2002) dan Supartini (2004), pencegahan cedera dapat dilakukan dengan memberikan pengamanan di sekitar anak usia toddler yaitu sebagai berikut:

1) Pengamanan secara umum

a) Tidak meletakkan pisau atau benda tajam dan berbahaya sembarangan*.

b) Menyimpan zat-zat berbahaya sehingga jauh dari jangkaun anak-anak*.

c) Tidak meninggalkan anak sendirian tanpa pengamanan.

d) Jangan menidurkan bayi di tempat yang tinggi, karena dapat terguling dan jatuh.

e) Mengganti popok bayi di lantai atau di atas kasur berselimut tebal.

f) Anak yang agak besar harusdi jauhkan dari obat-obatan, racun tikus, racun serangga, minyak tanah, sabun, detergen, dan peralatan mandi. Barangbarang tersebut harus diletakkan ditempat yang jauh dari jangkauan anak-anak. Sebab, anak-anak sangat menyukai benda-benda yang mencolok dan dapat dijadikan mainan*.

g) Tidak membiarkan anak bermain sendiri di dalam air, di kolam, atau diember. Anak-anak memang mempunyai sifat suka bermain air dan selalu ingin tahu dengan hal-hal baru. Jangan biarkan anak berada dekat sumur, kolam, sungai, tanpa pengawasan orang tua.

h) Jika rumah dekat dengan jalan raya, pintu rumah dan pintu pagar pastikan terkuci diberi pembatas yang tidak dapat dilangkahi anak-anak. Jangan biarkan anak berada dekat jalan raya tanpa pengawasan orang dewasa*.

i) Hindari anak dari benda panas seperti: kompor, setrika, termos/dispenser air panas, tempat pembakaran sampah*.

2) Pengamanan di dalam rumah

a) Jika anak sudah mulai berjalan, pastikan dia tidak terjatuh akibat lantai yang terlalu licin atau terlalu kotor. Jaga lantai rumah selalu bersih dan kering. 
Jaga anak apabila lantai baru di pel dan segera di lap jika ada air atau cairan tumpah*.

b) Di dalam ruangan tidak ada perabot yang tersudut runcing*.

c) Di samping itu harus diusahakan tidak meletakkan benda-benda berbahaya, seperti pot bunga atau lampu di tempattempat yang mudah dijangkau anak*.

d) Jangan ada benda-benda beracun di sekitar ruangan seperti obat-obatan, baygon, cairan pembersih lantai, pestisida, lem, dan lainnya simpan di dalam lemari terkunci. Khusus untuk obat-obatan dapat dibuat lemari khusus yang ditempel di dinding yang tidak dapat dijangkau anak*.

e) Usahakan bayi tidur di boks, bukan di tempat tidur. Pastikan bahwa boks tempat tidur aman, berpagar kuat, catnya tidak beracun atau nontoxic, jeruji pagarnya tidak terlalu renggang agar bayi tidak dapat memasukkan kepalanya ke sela-sela jeruji. Anak yang agak besar usahakan tidak tidur di tempat tidur bertingkat atas.

f) Tidak meninggalkan anak di kamar mandi sendirian, sebab dia akan main air dan dapat tenggelam atau tersedak air.

g) Jika sedang memandikan, tetapi mendadak ada tamu datang, segera keringkan bayi secepatnya.

h) Jauhkan peralatan dapur yang berisi air panas atau minyak panas dari jangkauan anak-anak*.

i) Periksa peralatan masak agar tetap berfungsi baik: kompor tidak bocor, tabung gas memiliki pengaman, selang atau pipa gas tidak rusak, termos atau dispenser terletak di tempat aman.

j) Jika memiliki anak kecil, hindari penggunaan taplak meja karena anak senang atau mudah menariknya, dan benda-benda yang ada di atas meja akan berhamburan menimpa anak*.

k) Selalu syaratkan anak menggunakan helm ketika mengendarai mainan yang beroda.

1) Benda-benda kecil, seperti manikmanik, perhiasan, jarum, mainan kecil, alat tulis seperti penghapus, harus disimpan didalam laci yang tertutup rapat dan terkunci*.

m) Jika di rumah terdapat tangga, sebaiknya terdapat pegangan dan diberi pintu agar anak tidak dapat naik-turun sendiri. Bagi yang letak rumahnya di tepi jalan raya, sebaiknya ada pintu pagar yang harus selalu terkunci rapat*.

n) Kabel-kabel listrik dan peralatan elektrolik tidak ada yang terbuka, lecet, atau putus yang dapat menyebabkan anak terkena strum. Atur kabel supaya tidak terlalu panjang sehingga tidak terjuntai ke bawah dan dapat di jangkau anak*.

o) Apabila rumah menggunakan sumber air dengan sumur gali, buat selongsongnya, dan tempat penyimpanan air kemudian tutup dengan alat yang tidak dapat dibuka anak*.

p) Alat makan dan minum yang terbuat dari bahan yang dapat pecah karena apabila anak menggunakannya kemudian pecah, hal ini berisiko terjadi perlukaan pada anak*.

q) Adanya parit di depan atau di samping rumah walaupun kecil, tetapi jika parit tidak tertutup, anak-anak yang bermain dipinggirnya dapat terjatuh*.

r) Stop kontak terpasang ditempat yang tidak dapat dijangkau anak, karena anak 
penasaran ingin memegang, bahkan mencoloknya dengan jari atau benda lain*.

3) Pengamanan di luar rumah

a) Sebaiknya tidak membiarkan anak bermain sendiri di luar rumah.

b) Jika anak bermain di luar, pastikan bahwa tempat main dan jenis permainannya aman atau tidak berbahaya.

c) Sebaiknya anak dilarang bermain di jalan raya atau bermain panjat-panjatan tanpa pengawasan.

d) Alas tempat bermain harus empuk, hindari tempat bermain yang memiliki permukaan kasar, seperti lantai yang kasar atau yang keras.

e) Jika anak mendapat kecelakaan, segera lakukan penanggulangan. Orangtua harusmengetahui pengetahuan dasar yang menyangkut cara-cara menangani kecelakaan pada anak.

f) Ajarkan toddler untuk menghindari hewan yang tidak di kenal.

g) Mulai ajarkan toddler mengenai melihat kendaraan ketika menyebrang jalan, tetapi selalu bawa atau pegang tangan toddler ketika menyebrangi jalan maupun ada diantara pejalan kaki.

h) Ajarkan dan dukung penggunaan kursi di mobil yang menghadap ke belakang secara tepat sampai anak berusia 2 tahun dan kursi mobil yang menghadap ke depan setelah anak berusia 2 tahun untuk mengurangi risiko cedera pada toddler yang berhubungan dengan kendaraan bermotor.

i) Ajarkan toddler untuk tetap menjauh dari jalanan dan memberikan supervisi konstan untuk mencegah kecelakaan pejalan kaki.
Keterangan untuk yang diberi tanda (*) adalah kritikal point.

\section{METODE PENELITIAN}

Desain penelitian menggunakan metode deskriptif korelasi dengan pendekatan crosssectional.Sampel dalam penelitian ini adalah ibu yang mempunyai anak usia (1 sampai 3 tahun) di RW 01 Kelurahan Manggahang wilayah Puskesmas Jelekong Kabupaten Bandung dengan cara purposive sampling, dengan kriteria sampel Ibu yang setiap hari merawat dan mengasuh anaknya sendiri. Pengumpulan data dilakukan dengan cara membagikan kuesioner kepada responden serta untuk praktik pencegahan cedera mengacu pada pedoman observasi tindakan. Instrumen yang digunakan berbentuk koesioner pengetahuan dan lembar observasi yang dibuat sendiri oleh peneliti dan telah dilakukan uji validitas dengan korelasi pearson product moment dengan hasil $r$ table 0,444; dan hasil uji reliabilitas dengan cronbach alpha koesioner pengetahuan didapatkan hasil 0,913 dan pedoman observasi 0,863 sehingga pertanyaan dalam koesioner dan pedoman observasi dinyatakan reliabel. Observasi dilakukan secara langsung dan dilakukan tanpa sepengetahuan responden, hal ini dilakukan agar praktik cedera yang diamati berlangsung wajar atau alami. Data dianalisis secara univariat dan bivariat. Analisis univariatdisajikan dalam bentuk distribusi frekuensi dan persentase tiap variabel (Notoatmodjo, 2010) dan analisis bivariat untuk mengetahui hubungan sikap ibu tentang antisipasi cedera dengan praktik pencegahan cedera dianalisis menggunakan uji chisquare $\left(\mathrm{x}^{2}\right)$. 


\section{HASIL PENELITIAN}

Dari hasil penelitian yang berjudul Hubungan Pengetahuan Tentang Antisipasi Cedera dengan Praktik Pencegahan Cedera pada Anak Usia Toddler di RW 01 Kelurahan Manggahang Wilayah Puskesmas Jelekong Kabupaten Bandung terhadap 79 responden diperoleh hasil sebagai berikut:

Tabel 1.

Gambaran Pengetahuan Ibu tentang Antisipasi Cedera Pada Anak Usia Toddler (1-3 Tahun)

\begin{tabular}{ccc}
\hline Pengetahuan & Jumlah & Persentase (\%) \\
\hline Baik & 25 & $31,6 \%$ \\
Cukup & 35 & $44,3 \%$ \\
Kurang & 19 & $24,1 \%$ \\
\hline Total & $\mathbf{7 9}$ & $\mathbf{1 0 0} \%$ \\
\hline
\end{tabular}

Sumber : data primer penelitian, 2016

Hasil analisa dapat diketahui bahwa sebagian dari responden mempunyai pengetahuan cukup yaitu sebanyak 35 orang $(44,3 \%)$ dan sangat sedikit dari responden yang pengetahuannya kurang yaitu 19 orang $(24,1 \%)$.

Tabel 2.

Gambaran Sikap Ibu tentang Antisipasi Cedera Pada Anak Usia Toddler (1-3 Tahun)

\begin{tabular}{ccc}
\hline Sikap & Jumlah & Persentase (\%) \\
\hline Sikap Positif & 44 & $55,7 \%$ \\
Sikap Negatif & 35 & $44,3 \%$ \\
\hline Total & $\mathbf{7 9}$ & $\mathbf{1 0 0} \%$ \\
\hline
\end{tabular}

Sumber : data primer penelitian, 2016

Hasil analisa menunjukkan bahwa sebagian dari responden memiliki sikap positif dalam antisipasi cedera pada anak usia toddler yaitu 44 orang $(55,7 \%)$.

Tabel 3.

Hubungan Pengetahuan Ibu tentang Antisipasi Cedera dengan Praktik Pencegahan Cedera pada Anak Usia Toddler (1-3 Tahun)

\begin{tabular}{lccccccc}
\hline \multirow{2}{*}{ Pengetahuan Ibu } & \multicolumn{3}{c}{ Praktik Pencegahan Cedera } & \multicolumn{2}{c}{ Total } & \multirow{2}{*}{ P value } \\
& $\mathrm{N}$ & $\%$ & $\mathrm{~N}$ & $\%$ & $\mathrm{~N}$ & $\%$ & \\
\hline Baik & 24 & 96,0 & 1 & 4,0 & 25 & 100 & 0,000 \\
Cukup & 16 & 45,7 & 19 & 54,3 & 35 & 100 & \\
Kurang & 0 & 0,0 & 19 & 100 & 19 & 100 & \\
\hline Total & $\mathbf{4 0}$ & $\mathbf{5 0 , 6}$ & $\mathbf{3 9}$ & $\mathbf{4 9 , 4}$ & $\mathbf{7 9}$ & $\mathbf{1 0 0}$ & \\
\hline
\end{tabular}

Sumber : data primer penelitian, 2016

Berdasarkan hasil analisa menunjukkan responden yang berpengetahuan baik hampir seluruhnya memiliki praktik pencegahan cedera yang baik sebanyak 24 orang (96\%), sedangkan responden yang mempunyai pengetahuan kurang seluruhnya mempunyai praktik pencegahan cedera yang tidak baik yaitu 19 orang (100\%). Hasil uji statistik didapatkan nilai $\mathrm{P}$ value $0,000<\alpha(0,05)$ maka 
dapat disimpulkan $\mathrm{H}_{\mathrm{o}}$ ditolak dengan demikian ada hubungan antara pengetahuan tentang antisipasi cedera dengan praktik pencegahan cedera pada anak usia toddler.

\section{HASIL PENELITIAN}

Berdasarkan hasil penelitian pada tabel 1 . dapat diketahui bahwa sebagian dari ibu $(44,3 \%)$ mempunyai pengetahuan cukup tentang antisipasi cedera pada anak usia toddler. Hal ini disebabkan sebagian ibu sudah mengetahui tentang antisipasi cedera pada anak usia toddler (1-3 tahun), berdasarkan tingkatan pengetahuan ibu tidak hanya tahu tetapi dapat memahami dan mengaplikasikan, hal ini dapat dibuktikan bahwa ibu dapat meramalkan kemungkinan bahaya atau ancaman kecelakaan yang bisa terjadi sesuai dengan tumbuh kembang anak usia toddler. Salah satunya dalam kemampuan menggambarkan tempat-tempat didalam dan disekitar rumah yang dapat menyebabkan cedera terjadi. Para ibu juga mengakui bahwa saat anaknya beraktifitas sebisa mungkin ibu dapat menggunakan alat permainan yang aman dan menjamin tempat bermain anak yang tidak mengancam keselamatan anaknya.

Hal tersebut sesuai dengan teori yang dikemukakan oleh Supartini (2004) bahwa orang tua khususnya ibu perlu mendapatkan bimbingan antisipasi terhadap kemungkinan terjadinya bahaya atau ancaman kecelakaan karena cedera pada anak usia toddler tidak terjadi apabila orang tua memiliki pengetahuan tentang tingkat tumbuh kembang anak usia toddler. Para ibu juga mendapatkan cukup informasi yang didapatkan baik dari media elektronik seperti televisi, radio, ataupun internet maupun media cetak seperti koran dan buku majalah. Walaupun ibu tidak cukup sering mencari informasi yang berkaitan dengan kegiatan antisipasi cedera pada anak. Para ibu mendapatkan informasi baik secara langsung maupun tidak langsung mengenai antisipasi cedera pada anak, tetapi dalam hal ini ibu masih kurang mampu memahami secara mendalam dan mengaplikasikan informasi yang didapat, dari data secara umum didapatkan bahwa sebagian besar ibu berpendidikan SMA. Latar belakang pendidikan ibu mempengaruhi pengetahuan ibu tentang antisipasi cedera pada anak usia toddler.

Berdasarkan analisa dalam penelitian yang dilakukan oleh Atak, et.al (2010), ditemukan bahwa semakin meningkatnya pendidikan ibu maka ibu lebih dapat mengidentifikasi resiko cedera pada anak. Hal ini sesuai dengan teori yang dikemukakan oleh Mubarak (2007) yang menyatakan bahwa makin tinggi pendidikan seseorang makin mudah menerima informasi, dan pada akhirnya makin mudah pula pengetahuan dimilikinya.Oleh karena itu pengetahuan ibu mengenai antisipasi cedera pada anak usia toddler menjadi sangat penting agar ibu dapat selalu waspada terhadap setiap gerak yang dilakukan oleh anak, memberikan alat bermain yang sesuai dan tidak membahayakan, dan dapat memberikan pemahaman pada anak tentang cara melindungi diri dari cedera sehingga dapat mencegah kematian ataupun kecacatan akibat cedera yang dapat menyebabkan terganggunya proses tumbuh kembang anak dikemudian hari.

Pada tabel 2. menunjukkan bahwa sebagian dari responden memiliki sikap positif dalam antisipasi cedera yaitu 44 orang $(55,7 \%)$. Dimana hal tersebut dapat dipengaruhi oleh pengetahuan yang ibu miliki, dimana sebagian dari responden memiliki pengetahuan yang cukup $(44,3 \%)$. Menurut Notoatmodjo (2010) pengetahuan, pikiran, keyakinan dan emosi memegang peranan penting dalam menentukkan sikap. Anak usia 
toddler mempunyai rasa ingin tahu yang besar untuk itu harus diperhatikan keamanan dan keselamatan anak. Peran ibu yang terpenting adalah untuk menghindari kecelakaan pada anak dengan memberikan pengawasan dan perhatian penuh dalam proses bermain dan belajar anak. Sikap positif tentang antisipasi cedera pada anak usia toddler perlu ibu miliki karena kurangnya pengawasan merupakan penyebab terjadinya cedera, ibu perlu mendampingi serta memberi arahan ketika anak beraktifitas, bahkan bila cedera terjadi ibu dapat bersikap tidak panik dan dapat melakukan penanganan cedera dengan benar (Mohammad, 2005).

Dalam penelitian ini sebagian dari responden memiliki sikap negatif $(44,3 \%)$ hal ini disebabkan karena masih ada responden yang pengetahuannya kurang $(24,1 \%)$. Menurut Azwar (2007) pengetahuan merupakan suatu bentuk dalam sistem pendidikan yang memiliki pengaruh besar dalam pembentukan sikap. Selain itu, sikap negatif juga dipengaruhi oleh pengalaman ibu. Karakteristik individu berperan dalam pembentukkan perilaku kesehatan seseorang serta dipengaruhi oleh faktor kebudayaan dan kepercayaan yang ibu miliki. Banyak dari ibu yang belum punya pengalaman anaknya mengalami cedera, sehingga ibu meyakini bahwa antisipasi cedera tidak perlu dilakukan karena anak kecil tidak banyak hal yang bisa dilakukan oleh anak, bila cedera terjadi tidak akan menimbulkan sesuatu yang fatal. Ibu menganggap pengawasan tidak harus selalu dilakukan karena dilingkungannya anaknya bersama dengan anak lain yang lebih besar.

Hasil analisis terdapat hubungan antara pengetahuan ibu tentang antisipasi cedera dengan praktik pencegahan cedera pada anak usia toddler (pvalue 0,000). Menurut Mubarak (2012) pengetahuan merupakan salah satu dari faktor yang dapat mempengaruhi praktik seseorang. Maka dapat disimpulkan jika pengetahuan ibu kurang tentang antisipasi cedera, maka ibu akan cenderung melakukan praktik pencegahan cedera yang tidak baik, yang mana hal ini dapat menyebabkan anak beresiko mengalami cedera. Kejadian cedera anak terbanyak dialami oleh ibu dengan tingkat pendidikan rendah.

\section{PENUTUP}

\section{Kesimpulan}

Gambaran pengetahuan ibu tentang antisipasi cedera pada anak usia toddler di RW 01 Kelurahan Manggahang Wilayah Puskesmas Jelekong Kabupaten Bandung yaitu sebagian dari ibu mempunyai pengetahuan cukup $(44,3 \%)$, sebagian dari ibu memiliki sikap yang positif $(55,7 \%)$ dan terdapat hubungan antara pengetahuan ibu tentang antisipasi cedera dengan praktik pencegahan cedera pada anak usia toddler di RW 01 Kelurahan Manggahang Wilayah Puskesmas Jelekong Kabupaten Bandung ( $\mathrm{P}$ value $=0,000<\alpha=$ 0,05).

\section{Saran}

Petugas kesehatan di wilayah puskesmas jelekong diharapkan dapat menerapkan program pendidikan kesehatan kepada para kader-kader posyandu tentang bimbingan antisipasi cedera. Sehingga kader bisa memberikan pelayanan bimbingan antisipasi cedera kepada masyarakat agar dapat mempraktikkan pencegahan cedera dengan mempertinggi kemampuan dalam upaya meningkatkan kesehatan anak sehingga bisa memperkecil angka kejadian cedera pada anak usia toddler.

\section{DAFTAR PUSTAKA}


Adriana, D. (2011). Tumbuh Kembang dan Terapi Bermain pada Anak. Jakarta : Salemba Medika.

Agran, P.F., Anderson, C., Winn, D., Trent, R., Haynes, L.W., Thayer, S. (2005). Ratesof Pediatric Injuries By 3-Month Intervals For Children 0-3 Years of Age. Journal of Pediatrics. 683-692.

Aken, C.V., Junger M., Verhoeven, M., Aken, G.V., Dekovic, M. (2007). Externalizing Behaviors and Minor Unintentional Injuries In Toddlers. Journal of Pediatric Psychology. 230244.

Alwi, Hasan. (2016). Kamus Besar Bahasa Indonesia. Edisi Kelima: Jakarta: Balai Pustaka.

Ari, Sulistyawati. (2014). Deteksi Tumbuh Kembang Anak. Jakarta: Salemba Medika.

Arikunto, S. (2010). Prosedur Penelitian Suatu Pendekatan Praktik. Jakarta: Rineka Cipta.

Atak, N., Karaoğlu, L., Korkmaz, Y., Usubütün, S. A Househ old Survey. (2010). Unintentional Injury Frequency and Related Factors Among Children Under Five Years In Malatya. The Turkish Journal of Pediatrics. 285-293.

Azwar, Saifuddin. (2012). Metode Penelitian. Yogyakarta: Pustaka Pelajar.

Badan Litbang Kesehatan. (2013). Laporan Hasil Riset Kesehatan Dasar Riskesdas Tahun 2013. Jakarta: Kementrian Kesehatan RI.

Barbara, Kozier. (2010). Buku Ajar Fundamental Keperawatan, Edisi 7 Volume 1. Jakarta: EGC.

Budiman. (2011). Penelitian Kesehatan, Buku Pertama. Bandung: Refika Aditama.
Budiman, dan Riyanto Agus. (2013). Pengetahuan dan Sikap dalam Penelitian Kesehatan. Jakarta: Salemba Medika.

Chomaria, Nurul. (2015). Tumbuh Kembang Anak Usia 0-5 Tahun. Surakarta: Cinta.

Depkes RI, (2007). Stimulasi, Deteksi dan Intervensi Dini Tumbuh Kembang Anak Ditingkat Pelayanan Dasar. Jakarta : Depkes RI.

Espeland, N. (2005). Panduan Keselamatan Anak. Jakarta: Prestasi Pustakakarya.

Hidayat, A. A. (2008). Metode Penulisan Keperawatan dan Teknik Analisa Data. Jakarta: Salemba Medika.

Kuschithawati, S., Magetsari, R., Nawi. (2007). Faktor Risiko Terjadinya Cedera Pada Anak. Jurnal Berita Kedokteran Masyarakat, 23(3),131141.

Kyle, Terri, Susan Carman. (2014). Buku Ajar Keperawatan Pediatrik. Volume 1. Jakarta: EGC.

Mary E. (2008). Panduan Belajar: Keperawatan Pediatrik. Jakarta: EGC National.

Meadow \& Newell. (2005). Lecture Notes: Pediatrika. Jakarta: PT. Erlangga.

Mohammad, K. (2005). Pertolongan Pertama Pada Cedera. Jakarta: Gramedia.

Mubarok, W.I. (2007). Promosi Kesehatan: Sebuah Pengantar Proses Belajar Mengajar dalam Pendidikan. Yogyakarta: Graha Ilmu Muscary.

Notoatmodjo, Soekidjo. (2012). Promosi Kesehatan dan Perilaku Kesehatan. Jakarta: Rineka Cipta. 
Nursalam, (2008), Konsep dan Penerapan Metodologi Penelitian Ilmu Keperawatan. Jakarta: Salemba Medika.

Potter, P.A, Perry, A.G. (2005). Buku Ajar Fundamental Keperawatan: Konsep, Proses,dan Praktik. Edisi 4. Jakarta: EGC.

Purwanto, Heri. (2006). Pengantar Perilaku Manusia Untuk Keperawatan. Jakarta: EGC.

Purwoko, S. (2006). Pertolongan Pertama dan RJP Pada Anak. Edisi 4. Jakarta: Arcan.

Riduan. (2012). Dasar-Dasar Statistika. Cetakan kesepuluh. Bandung. Alfabeta.

Riyadi, Sujono, Sukarmin. (2009). Asuhan Keperawatan pada Anak, Edisi 1. Yogyakarta: Graha Ilmu

Riyanto, A.(2011). Pengolahan dan Analisis Data Kesehatan. Yogyakarta: Nuha Medika.
Santrock, J. W. (2007). Psikologi Perkembangan, Edisi 11 Jilid 1. Jakarta: Erlangga.

Soetjiningsih. (2012). Tumbuh Kembang Anak. Jakarta: EGC.

Sukarmin, Y. (2006). Petunjuk Praktis Pencegahan Kecelakaan dalam Proses Pembelajaran. Jurnal Pendidikan Jasmani Indonesia, 5(1):72-81.

Yulaelawati, Ella. (2015). Menjadi Orang Tua Pintar. Jakarta: PT. Mizan Publika.

Yiniarti, Sri. (2015). Asuhan Tumbuh Kembang Neonatus Bayi-Balita dan Anak Pra Sekolah. Bandung: PT. Refika Aditama.

Wasis. (2008). Pedoman Riset Praktis Untuk Profesi Perawat. Jakarta: EGC.

Wawan, A dan Dewi, M. (2010). Teori dan Pengukuran Pengetahuan, Sikap dan Perilaku Manusia. Yogyakarta: Nuha Medika.

Wong. (2008). Buku Ajar Keperawatan Peditrik, Volume 2. Jakarta: EGC. 